\title{
Sistema de información para la caracterización de imágenes de desgaste en álabes de rotor de una turbina de gas
}

\section{Information system for characterizing wear images on gas turbine rotor blades}

\author{
VILLAGRÁN-VILLEGAS, Luz Yazmín†๋*’,”, PATIÑO-ORTIZ, Miguel’, HERNÁNDEZ-GÓMEZ, \\ Luis Héctor' y VELÁZQUEZ-MARTÍNEZ, Víctor"
}

'Instituto Politécnico Nacional, Escuela Superior de Ingeniería Mecánica y Eléctrica, Sección de Estudios de Posgrado e Investigación, Unidad Profesional Adolfo López Mateos "Zacatenco", Edificio 5 3er. Piso, Col. Lindavista, C.P. 07300, Ciudad de México.

"Universidad Veracruzana, Facultad de Ingeniería Mecánica Eléctrica, Av. Venustiano Carranza S/N, Revolución, C. P. 93390, Poza Rica; Veracruz, México.

ID $1^{\text {er }}$ Autor: Luz Yazmín, Villagrán-Villegas / ORC ID: 0000-0003-3860-2923, CVU CONACYT ID: 96365

ID 1er Coautor: Miguel, Patiño-Ortiz / ORC ID: 0000-0002-5630-8077, CVU CONACYT ID: 167388

ID 2do Coautor: Luis Héctor, Hernández-Gómez / ORC ID: 0000-0003-2573-9672, CVU CONACYT ID: 5107

ID $3^{\text {er }}$ Coautor: Víctor, Velázquez-Martínez / ORC ID: 0000-0001-5343-8346, CVU CONACYT ID: 799141

DOI: $10.35429 / \mathrm{JCS} .2020 .11 .4 .27 .34$

Recibido: 20 de Enero, 2020; Aceptado 30 de Junio, 2020

\section{Resumen}

En México, usuarios finales de turbinas de gas, en su norma NRF, solicitan, en adquisición de turbomaquinaria nueva, los diagramas de Goodman y Campbell. Sin embargo, no se tiene reportado el requerimiento de los diagramas cuando la turbina es enviada a un reacondicionamiento (overhaul). En este artículo de investigación, se sugiere que el usuario final, al efectuar un análisis de desgaste de un álabe de turbina, conozca con precisión las condiciones de un álabe en caso de pérdida total de la máquina $o$ en condiciones en las que envíe a reacondicionamiento uno o varios discos de turbina al fabricante, así mismo, las condiciones en las que se recibe después de su reparación o reacondicionamiento. El desgaste y la fricción son factores adversos que reducen la vida útil de un equipo mecánico. La pérdida de una cantidad relativamente pequeña de material, en ciertas localizaciones críticas de cualquier pieza mecánica, pueden marcar la diferencia entre el daño y el buen funcionamiento de la misma, por lo que esta investigación tiene como objetivo caracterizar imágenes de un álabe de turbina con el fin de identificar algún desgaste o falla mecánica; analizando las respuestas a variables determinísticas y no determinísticas, buscando respuestas que coadyuven en la detección temprana de alguna falla mecánica que evite la pérdida total de la turbina de gas en operación. Para alcanzar los objetivos planteados en esta investigación se usan técnicas y herramientas con un enfoque sistémico y sistemático, que permitirán la caracterización e interpretación de imágenes de álabes de turbinas de gas.

\begin{abstract}
In Mexico, the end user of gas turbines (PEMEX), in the NRF standard, requests the Goodman and Campbell diagrams for the acquisition of new turbo machinery. However, the requirement of the diagrams is not reported when the turbine is sent for overhaul. In this research article, it is suggested that the end user when carrying out a wear analysis of a turbine blade, know precisely the conditions of a blade in case of total loss of the machine or in conditions in which they send one or several turbine discs to the manufacturer and the conditions that receives after overhaul the discs. Wear and friction are the most adverse factors in reducing the useful life of mechanical equipment. The loss of a relatively small amount of material, in certain critical locations of any mechanical part, can make the difference between the damage and the good functioning of the gas turbine, so this research aims to characterize images of a turbine blade with in order to identify any wear or mechanical failure; analyzing the responses to deterministic and non-deterministic variables, looking for responses that contribute to the early detection of any mechanical failure that prevents the total loss of the gas turbine in operation. To achieve the objectives set out in this research, techniques and tools with a systemic and systematic approach are used, which will allow the characterization and interpretation of images of gas turbine blades.
\end{abstract}

Blades, Gas turbine, Systems, Images analysis

Álabes, Turbina de gas, Sistemas, Análisis de imágenes

Citación: VILLAGRÁN-VILLEGAS, Luz Yazmín, PATIÑO-ORTIZ, Miguel, HERNÁNDEZ-GÓMEZ, Luis Héctor y VELÁZQUEZ-MARTÍNEZ, Víctor Sistema de información para la caracterización de imágenes de desgaste en álabes de rotor de una turbina de gas. Revista de Simulación Computacional. 2020. 4-11:27-34.

\footnotetext{
* Correspondencia al Autor (Correo electrónico: yvillagran@uv.mx)

$\dagger$ Investigador contribuyendo como primer autor
} 


\section{Introducción}

La estructura de esta investigación contempla tres etapas, resultados y conclusiones. En la primera etapa se describen las características generales de las turbinas aeroderivadas para aplicaciones costa afuera, los elementos principales de una turbina de gas y los mecanismos de degradación de materiales en la turbina, en específico, los álabes de compresor axial. A partir de esto, se plantea el caso de estudio y la metodología a seguir. En la segunda etapa se describe el diseño del sistema que permitirá efectuar la caracterización de imágenes de desgaste de álabes de compresor axial, se describe el procesamiento digital de imágenes y se efectúa la propuesta del diseño del modelo sistema-vista-controlador. La tercera etapa presenta la caracterización de imágenes de desgaste en la imagen de un álabe de la $7^{\mathrm{a}}$. Etapa del compresor axial de una turbina de gas de 4700 H.P. Para el reconocimiento y caracterización del desgaste en álabes se aplican filtros a las imágenes.

Las turbinas de gas aeroderivadas son utilizadas en la producción de energía eléctrica en plantas industriales $y$ en instalaciones petroleras; entre sus principales características esta su gran confiabilidad y su alta relación potencia/peso. Al tener menos peso que las turbinas convencionales son más simples de instalar y su arranque es sencillo. Sin embargo, debido a que tienen menos masa es difícil detectar las vibraciones ante fallos en el funcionamiento. Las turbinas de gas aeroderivadas tienen dos componentes básicos; un generador de gas y una turbina de potencia, la turbina de potencia no es acoplada mecánicamente, su acoplamiento es aerodinámico [1].

El medio ambiente juega un papel relativamente pasivo en el ciclo de operación de una turbina de gas, ya que existen condiciones atmosféricas que pueden afectar su funcionamiento y periodo de vida útil [2]. La acción principal de los álabes del rotor es aumentar la velocidad del aire y la presión dinámica, pues dicho rotor recoge la energía que le entrega la turbina. La presión estática aumenta también en el rotor, pues en el diseño de los álabes (Figura 1), se les da mayor sección de salida que de entrada, lo que provoca un efecto difusor.

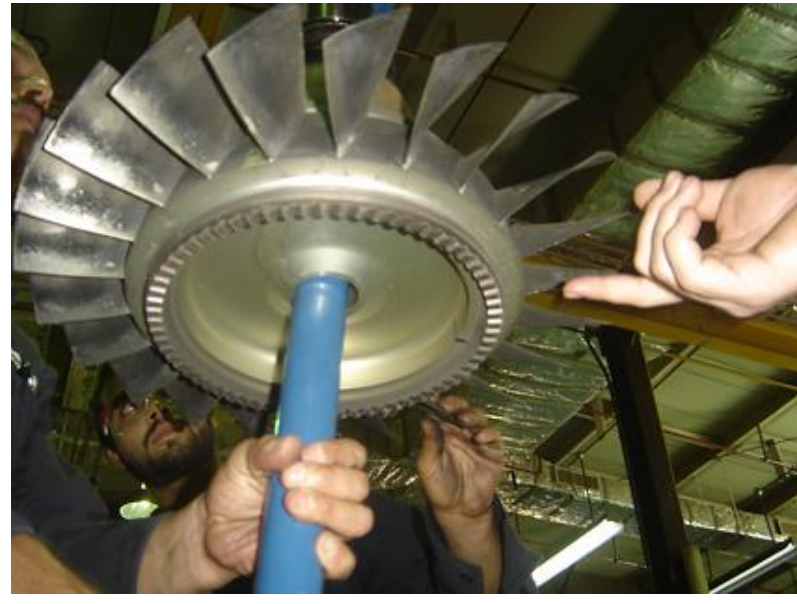

Figura 1 Álabe de rotor de un compresor axial.

Nota. Adaptado de Disco de compresor de turbina, Villagrán-Villegas Luz Yazmin, 2017

Fuente. Tesis doctorado y [3]

En las turbinas de gas, las temperaturas de operación son elevadas, y esto puede provocar su deterioro por fenómenos de oxidación y corrosión. El daño ocasionado por estos fenómenos hace imprescindible la búsqueda de mecanismos y nuevos materiales que permitan aumentar la vida en servicio de estos materiales. Los nuevos desarrollos han permitido disminuir la degradación de los sustratos, aumentando la vida útil de los componentes [4], retardando el proceso de oxidación. Para los álabes de turbinas de gas, los materiales más usados son las súper aleaciones de titanio o de níquel y las aleaciones de wolframio-molibdeno. El montaje sobre el rotor requiere especial cuidado, ya que se debe prestar una atención especial al ángulo óptimo.

La corrosión de los álabes del compresor puede ocurrir debido a la humedad que contiene las sales y los ácidos que se acumulan en él. Durante los años ochenta, GE introdujo un nuevo material para álabes de compresores, GTD-450, un acero inoxidable martensítico endurecido por precipitación para sus máquinas avanzadas y mejoradas, sin sacrificar la resistencia a la corrosión por tensiones. El GTD450 ofrece mayor resistencia a la tracción, resistencia a la fatiga de alto ciclo y resistencia a la fatiga por corrosión, en comparación con el tipo 403. GTD-450 también posee una resistencia superior a los ambientes de sal ácida al tipo 403, debido a una mayor concentración de cromo y presencia de molibdeno [5]. 
Los mecanismos que causan la degradación de la turbina [6]. son: incrustaciones, corrosión, corrosión en caliente, oxidación, erosión, abrasión, fusión de partículas y degradación mecánica.

En las instalaciones petroleras las pérdidas son evaluadas en barriles diarios de petróleo. Por ejemplo: Actualmente el Activo Nohoch-Alfa tiene una producción de $8,000 \mathrm{Bd}$, es decir \$388,960.00 US, y tiene instaladas cinco turbinas de gas, en las cuales en caso de falla se tendría que llamar al servicio técnico a bordo, en donde la falla tendría un costo de 56.864 Bd por cada ingeniero de servicio que se utilice, más la pérdida en producción. Por la importancia de los costos de fallas es necesario contar con técnicas y herramientas para efectuar análisis de los mecanismos de desgaste, a partir de la caracterización de imágenes, que permitan conocer y disminuir los paros no programados y las fallas en las turbinas de gas, debido a que, de acuerdo a la literatura consultada, existe un $40 \%$ de paros no programados por vibraciones en la sección de compresor y $10 \%$ de pérdida total de la turbina de gas, originada por partículas en el interior del compresor. De hecho, la mayor parte de los problemas en turbinas de gas son debido a daños que se presentan en los álabes de la sección de compresor axial, los cuales son resueltos con el re-alabeo a las 30,000 horas de operación, siendo el reacondicionamiento (overhaul) promedio cada 3-4 años de operación de un equipo.

Los modos de desgaste más frecuentes son severas acciones de picadura, sin embargo, los mecanismos de desgaste no son los mismos, cada caso es particular, dependiendo de su ubicación, latitud, ambiente y condiciones de operación y mantenimiento. En México, en Cantarell existen 600 unidades de turbogas instaladas, de las cuales 30 unidades son del tipo aeroderivada de 4,700 H. P., con un valor aproximado de $\$ 11,474,303.12$ US. El tamaño óptimo de las turbinas aeroderivadas mantiene una alta relación potencia-peso, que son factores clave en el mar, así como para la disponibilidad, confiabilidad y robustez.
Los usuarios finales son los que efectúan la reparación y reacondicionamiento de las turbinas de gas; pero en caso de requerir reparación de discos de turbina, éstos son enviados al fabricante. Partiendo de lo anterior, el objetivo de este trabajo es el desarrollo de una herramienta que permita efectuar el análisis de los mecanismos de desgaste de alabes de turbinas de gas a partir de la caracterización de imágenes, con el objetivo de reducir costos en este tipo de estudios, que actualmente oscilan en US $\$ 2,764.75$ [7].

\section{Metodología}

\section{A. Metodología Jenkins Wilson.}

La metodología Jenkins-Wilson consiste en cuatro fases las cuales facilitan la toma de decisiones y la solución de problemas.

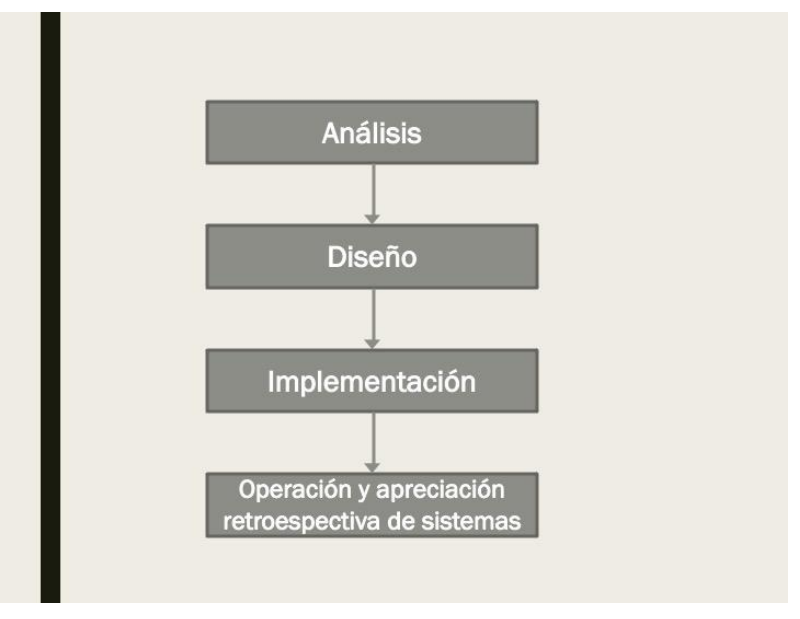

Figura 2 Metodología de Jenkins [8]

Nota. Adaptado de Metodología Jenkins, Brulé, J. y Bount, A., 1989

Fuente: Knowledge Acquisition Computing Mc. Graw Hill.

Fase 1: Análisis de Sistemas

Las actividades que se llevan a cabo en esta etapa son:

- $\quad$ Identificación y formulación del problema.

- $\quad$ Organización del proyecto.

- Definición del sistema.

- Definición del supra sistema.

- Definición de los objetivos del supra sistema. 
- $\quad$ Definición de los objetivos del sistema.

- Definición de las medidas de desempeño del sistema.

Recopilación de datos e información.

Las partes de la primera fase nos ayudan a tener una visión más clara del problema, para poder identificarlo y facilitar la toma de decisiones.

\section{Fase 2: Diseño de Sistemas}

Fase en la cual: se proporciona el ambiente futuro del sistema, se desarrolla un modelo cuantitativo del sistema, se efectúa una evaluación de las alternativas generadas y se selecciona la que optimice la operación del sistema. En esta fase se predicen los posibles resultados de las medidas a tomar para no obtener resultados inesperados y tener una clara visión del rumbo que llevan las acciones.

\section{Fase 3: Implantación de Sistemas}

Los resultados se deben presentar a los tomadores de decisiones, solicitar la aprobación para la implantación del diseño propuesto y se construye en detalle el sistema. En esta fase se busca implementar el sistema, después de cubrir todos los resultados posibles en la fase 2, para así obtener el mejor sistema.

Fase 4: Operación y apreciación retrospectiva de sistemas

Los resultados se deben presentar a los tomadores de decisiones, buscar la aprobación para la implantación del diseño propuesto y la construcción a detalle del sistema.

Una vez construido el sistema, se debe mantener en observación, ya que es muy importante la retroalimentación [9].

\section{B. $\quad$ Procesamiento digital de imágenes.}

El objetivo del procesamiento de imágenes es transformar o analizar una imagen para extraer nueva información que antes no era evidente. (Figura 3)
Una imagen óptica puede convertirse en una señal eléctrica con una cámara de video o dispositivo que contenga dicha función, esta acción cambia la imagen de ser una fuente de luz óptica a una señal eléctrica que varía continuamente. Dicha señal representa una imagen que se denomina analógica de una imagen o señal analógica.

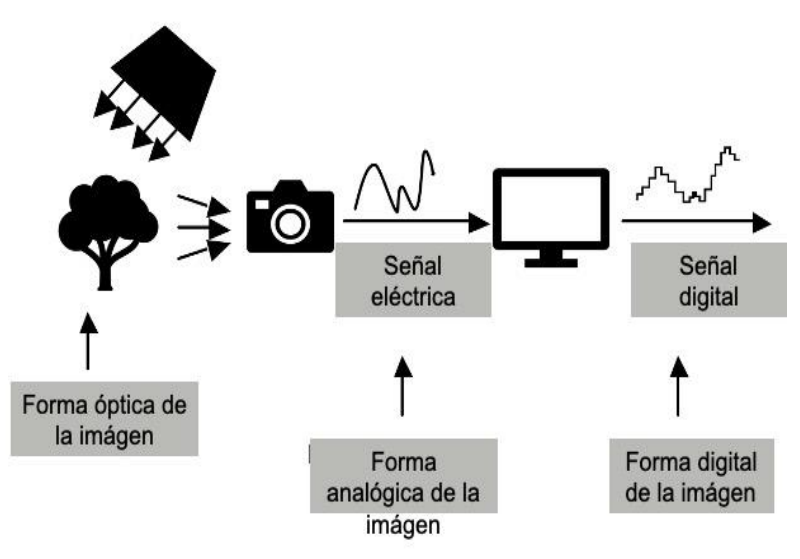

Figura 3 Representación gráfica de la digitalización de una escena [10]

Nota. Digitalización de imagen, Alcaniz, R., 2011

Fuente. Procesamiento Digital de Imagen.

Para el análisis de imágenes es necesario realizar una serie de pasos previos (Figura 4) con el fin de realizar un buen análisis de estas [11], por lo que es necesario revisar el paradigma propuesto por González y Woods [12], en el cual proponen lo siguiente:

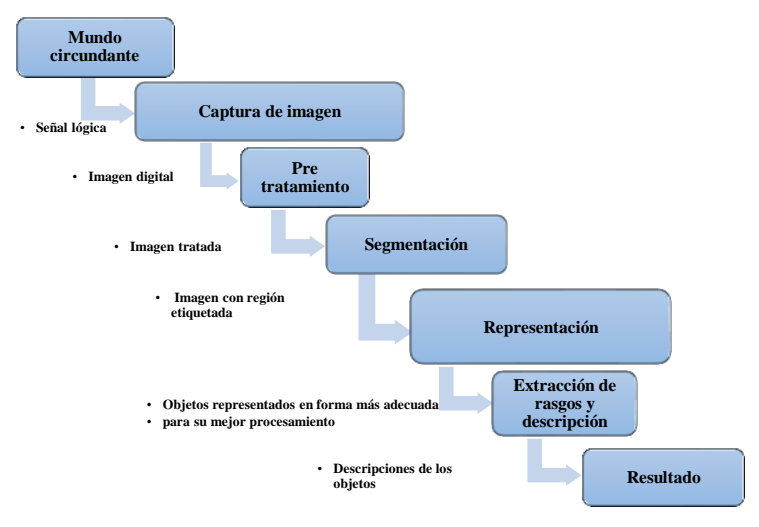

Figura 4 Esquema de captura de una imagen [12] Nota. Esquema de captura de una imagen, Sossa, H., 2019 Fuente. Procesamiento y análisis digital de imagen.

a) Formación de la imagen 
Una imagen es aquellos objetos iluminados por una o más fuentes de radiación, la cual es una representación óptica de los mismos, por lo tanto una imagen está formada por varios elementos, los cuales son: el objeto $\mathrm{u}$ objetos, la iluminación y el sistema de formación de imágenes. Por lo que es importante cuidar la iluminación, que debe ser considerada en los modelos matemáticos que quieran reflejar con fidelidad la realidad física.

b) Captación de una imagen

Un sistema óptico $(\mathrm{H})$ se modela como un sistema de desplazamiento no lineal e invariante, el cual tiene una respuesta tipo impulso $\mathrm{h}(\mathrm{x}, \mathrm{y})$, este sistema tiende a suprimir las altas frecuencia contenidas en la imagen $\mathrm{f}(\mathrm{u}$, v) por lo que la salida es una imagen borrosa $\mathrm{s}$ $(\mathrm{x}, \mathrm{y})$ comparada con la realidad. (Figura 5).

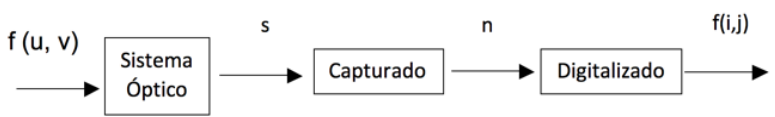

Figura 5 Esquema de captura de una imagen [12] Nota. Digitalización de imagen, Alcaniz, R., 2011 Fuente. Procesamiento Digital de Imagen

En casos prácticos la relación existente de la señal de entrada s $(x, y)$ y la corriente eléctrica de salida $\mathrm{n}(\mathrm{x}, \mathrm{y})$ es altamente no lineal $\mathrm{y}$, por tanto, el dispositivo de captación es aún una señal analógica bidimensional.

\section{c) Muestreo y cuantificación}

Para que la imagen analógica bidimensional se convierta de una señal continua a forma digital, se involucra un proceso de muestreo y cuantificación

La digitalización de las coordenadas se denomina muestreo de la imagen, mientras que la amplitud se conoce como cuantificación de los niveles de grises

Las imágenes digitales son un muestreo y cuantificación de señales de video obtenidas mediante sensores especializados. El muestreo es la tarea de discretización del escenario en el plano sensor. Dicha imagen es convertida en una matriz discreta cuyo tamaño es de $\mathrm{M} X \mathrm{~N}$ pixeles. El muestreo tiene una relación directa con la resolución espacial de la imagen.
Para determinar la resolución requerida para el análisis de la imagen y que los resultados sean satisfactorios, hay que observar y tener cuidado con dos factores en el muestreo, el primero es ¿cuál es la caracteriza más pequeña a observar dentro de la imagen? y la segunda es ¿cuál es el espacio que desea tomar?, por lo que la magnificación y la resolución de la imagen toma una gran importancia para el análisis de la imagen.

Un factor influyente dentro de la toma de imágenes es la iluminación (Figura 6), ya que esta puede influir en la toma de las imágenes y en una toma de decisión, la cual implica el área a tomar contra el factor del elemento más pequeño que se encuentre en la imagen.

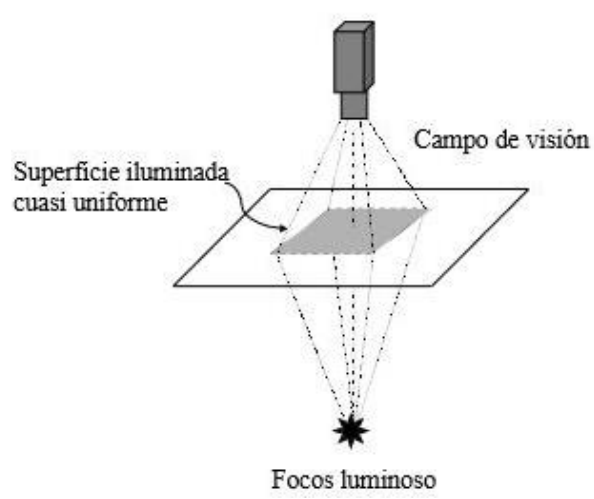

Figura 6 Esquema de captura de una imagen [12] Nota. Captura de imagen, Sossa, H., 2019

Fuente. Procesamiento y análisis digital de imagen

Para el diseño del sistema experto se propone implementar la arquitectura de Modelo Vista Controlador (MVC) ver Fig. 7, que consta de tres componentes:

Modelo: Se considera a la base de datos que se encarga de almacenar los datos, consultas $\mathrm{y}$ actualizaciones.

Vista: Es la parte visual del sistema que permite la interacción entre el usuario y el sistema, mantiene comunicación constante con el controlador del sistema, su función es encargarse exclusivamente de la manera en que se muestran los datos al usuario.

Controlador. Es la lógica del sistema y se encarga de gestionar las peticiones del usuario, se comunica con la base de datos para obtener la información necesaria, la procesa y finalmente se la entrega a la vista. 


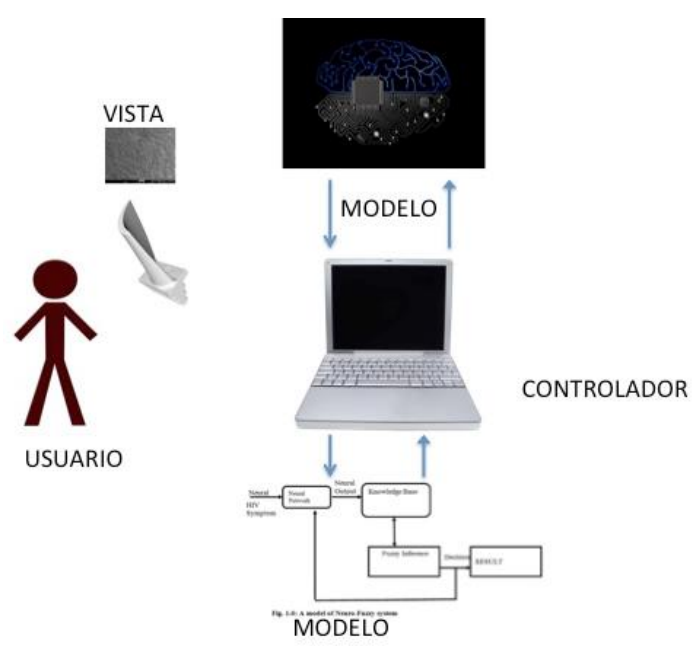

Figura 7 Modelo vista controlador del sistema Fuente: Elaboración Propia

Se selecciona este modelo por sus ventajas, como poder separar la lógica del controlador de los otros elementos, por lo que lo hace más escalable y permite realizar modificaciones al motor de inferencia sin tener que realizar ajustes en la base de datos ni en la vista, y se puede adaptar perfectamente a la construcción del sistema experto.

Adaptando el MVC en el diseño del sistema experto se tiene:

Modelo; base de datos que contiene, los umbrales y los pesos sinápticos (datos resultado del entrenamiento de la red neuronal), el registro de la caracterización de las imágenes del álabe de compresor axial (datos provenientes de la caracterización de las imágenes de mecanismos de desgaste) y una base de conocimiento. En la Figura 7 se presenta el diagrama de entidad relación propuesto para el modelo de base de datos del sistema. En la Figura 8 se puede apreciar una imagen de muestra el diseño propuesto de la vista.

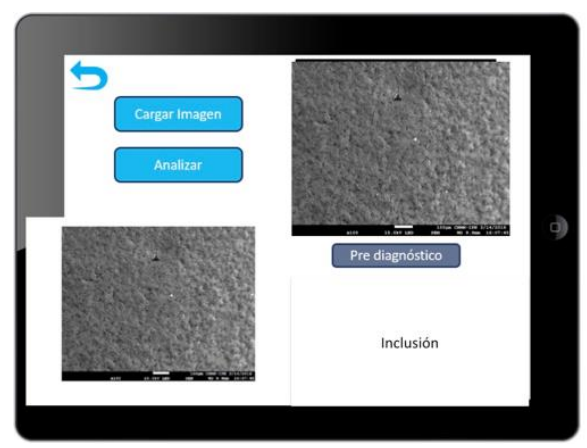

Figura 8 Ejemplo de la vista de un sistema. Fuente: Elaboración Propia

\section{Metodología}

La cadena de procesamiento para analizar y caracterizar imágenes se describe en las siguientes etapas [12]:

a) Pre-procesamiento. Operaciones para adaptar la información de una imagen y tener mejor análisis en pasos posteriores. Ejemplos de procesamiento son las operaciones de brillo y contraste.

b) Segmentación. Operaciones para hacer una partición de la imagen en varias regiones que representen la información necesaria para el problema a resolver.

c) Detección de objetos y clasificación. Determinación y clasificación de los objetos contenidos en la imagen.

d) Análisis de imagen. Obtener información de alto nivel acerca de lo que la imagen muestra.

\section{Resultados}

La Figura 9 muestra la superficie del álabe de turbina en diferentes zonas de daño, aquí es posible observar un daño provocado por el impacto de una partícula. En este álabe se efectuó un barrido de la muestra a $15 \mathrm{KV}$. Los filtros aplicados a la imagen del álabe realizan una operación de convolución entre la imagen a ser filtrada y una máscara. A continuación, se aplicarán los siguientes filtros: filtro de la media, sobel, logarítmico, laplaciano y gaussiano [13].

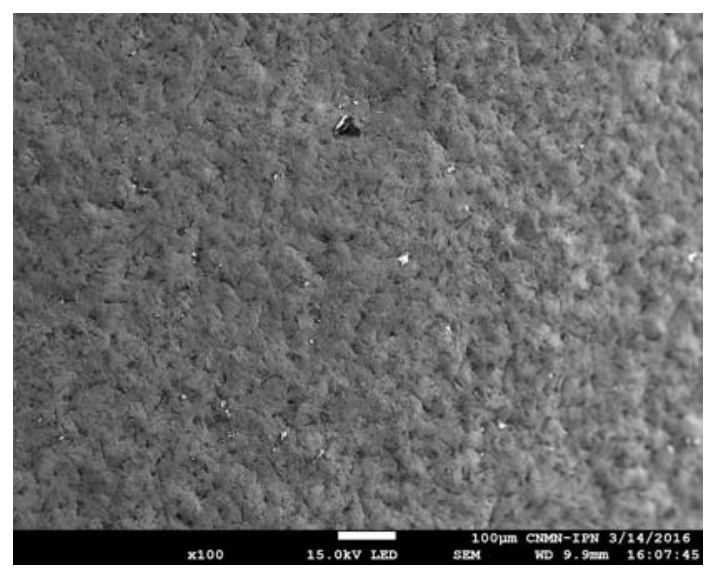

Figura 9 Álabe de rotor, $15 \mathrm{KV}$, microscopio eléctronico de barrido

Fuente: Elaboración propia 
Filtro de la media: Dada la imagen $f(i, j)$, el procedimiento consiste en generar una nueva imagen $g(i, j)$, cuya intensidad para cada píxel se obtiene promediando los valores de intensidad de los píxeles $f(i, j)$ incluidos en un entorno de vecindad predefinido.

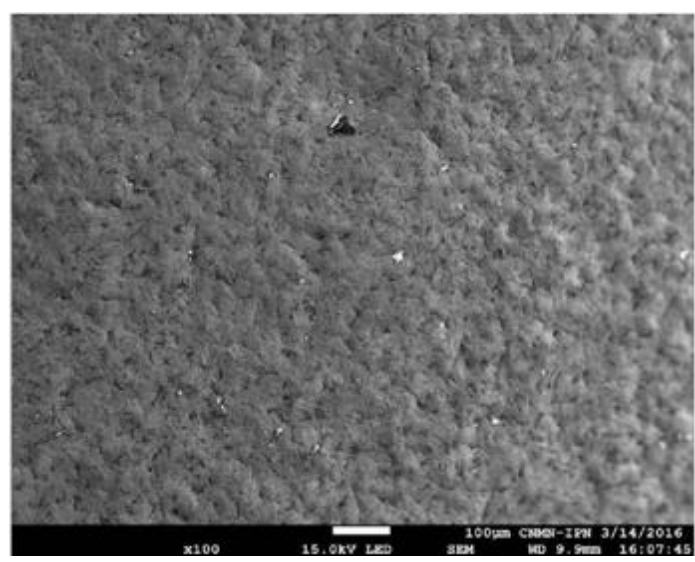

Figura 10 Álabe de rotor, $15 \mathrm{KV}$, microscopio eléctronico de barrido aplicando filtro de la media

Fuente: Elaboración propia

En la imagen de la Fig. 10 puede apreciarse la importancia de definir el tamaño de la máscara. Cuanto mayor sea ésta, se consigue una mayor reducción del ruido, pero a cambio se produce una mayor difuminación de los bordes. Aplicando la máscara de Sobel se obtiene:

$$
\begin{aligned}
& G x=(l 7+2 \cdot l 8+l 9)-(l 1+2 \cdot l 2+l 3) \\
& G y=(13+2 \cdot l 8+l 9)-(l 1+2 \cdot l 2+l 7)
\end{aligned}
$$

combinación de la

El cálculo del gradiente de la matriz horizontal y vertical.

$$
G=\sqrt[2]{G x^{2}+G y^{2}}
$$

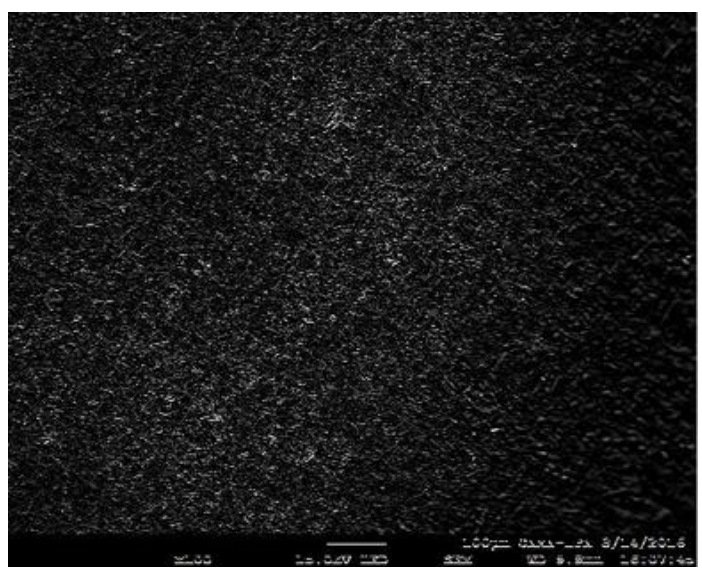

Figura 11 Álabe de rotor, $15 \mathrm{KV}$, microscopio eléctronico de barrido aplicando filtro Sobel

Fuente: Elaboración propia
El rango dinámico de una imagen (Fig. 11) puede comprimirse reemplazando cada valor de pixel por su logaritmo. Esto produce el efecto, que los valores de los pixeles de baja intensidad son intensificados. Aplicando el operador logaritmo a la imagen puede ser beneficioso en aplicaciones donde el rango dinámico puede ser demasiado largo para presentarlo en una pantalla. El operador logarítmico es un procesamiento del pixel simple, donde la función de muestreo es una curva logarítmica. Es decir, cada pixel es reemplazado con su logaritmo. La mayoría de las implementaciones aplican el logaritmo natural o el logaritmo en base 10 [14].

La función de muestreo del logaritmo viene dada por:

$$
G(i, j)=c \log (|P(i, j)|)
$$

Donde P y Q son las imágenes de entrada y salida, respectivamente, y c es el factor de escala. Dado que el logaritmo no está definido para el valor 0 , muchas implementaciones de este operador añaden el valor 1 a la imagen antes de aplicar el logaritmo. Este operador se define como:

$$
Q(i, j)=c \log (1+P(i, j))
$$

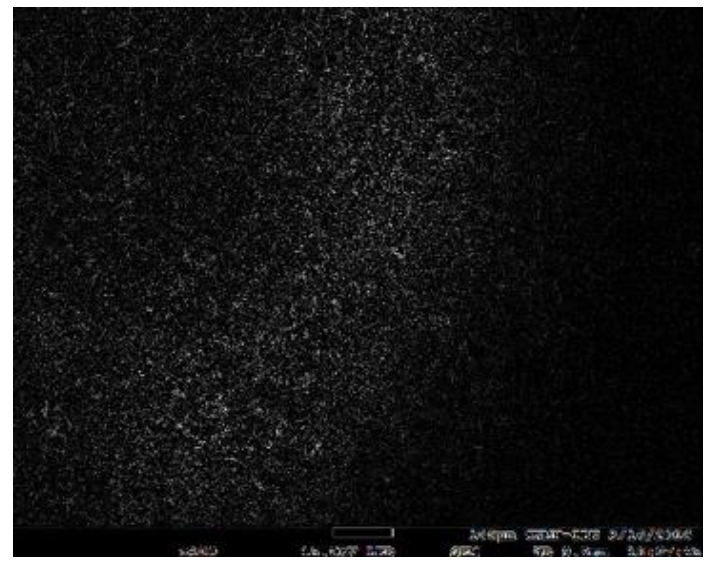

Figura 12 Álabe de rotor, $15 \mathrm{KV}$, microscopio eléctronico de barrido aplicando filtro Logarítmico

Fuente: Elaboración Propia

El operador del filtro Gaussiano (Fig.12) es un operador de convolución para imágenes que se utiliza para emborronar imágenes y eliminar detalles y ruido. En este sentido es similar al filtro de la mediana, pero este filtro utiliza una matriz de convolución distinta que representa la forma de la función de una función Gaussiana (en forma de campana).

VILLAGRÁN-VILLEGAS, Luz Yazmín, PATIÑO-ORTIZ, Miguel, HERNÁNDEZ-GÓMEZ, Luis Héctor y VELÁZQUEZ-MARTÍNEZ, Víctor Sistema de información para la caracterización de imágenes de desgaste en álabes de rotor de una turbina de gas. Revista de Simulación Computacional. 2020 
Esta matriz presenta algunas propiedades especiales. La distribución Gaussiana en una sola dimensión tiene la forma:

$$
Q(x)=\frac{1}{\sqrt{2 \pi \sigma}} e^{-\frac{x^{2}}{2 \sigma^{2}}}
$$

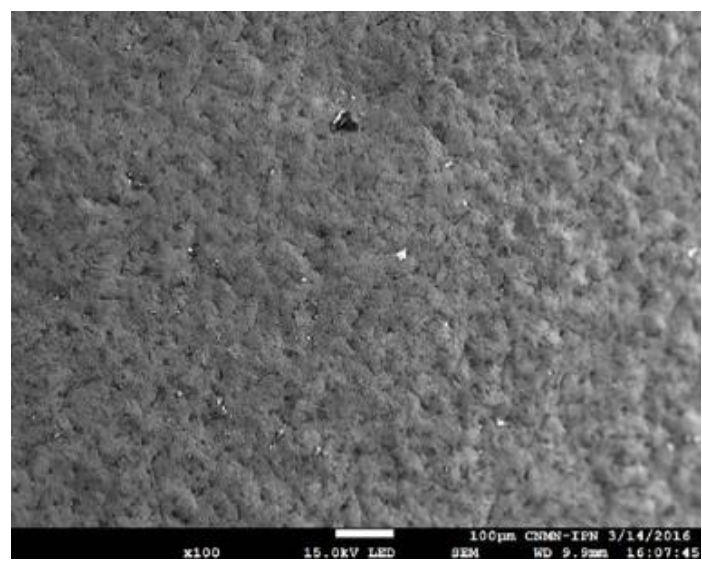

Figura 13 Álabe de rotor, $15 \mathrm{KV}$, microscopio eléctronico de barrido aplicando filtro Gaussiano.

Fuente: Elaboración propia

\section{Agradecimiento}

Los autores agradecen al Instituto Politécnico Nacional (IPN), México, por su apoyo para el desarrollo de este trabajo.

\section{Conclusiones}

Al aplicar a las imágenes un conjunto de filtros, se observa que el gaussiano permite un mejor análisis de los mecanismos de desgaste presentes en las muestras. El análisis de los resultados obtenidos, hasta el momento, ha permitido avanzar en el desarrollo de una herramienta que sirva de apoyo en la caracterización del desgaste en super aleaciones.

\section{Referencias}

[1] Boyce, M. P. (2002). Gas turbine engineering handbook (2a ed., Vol. 1). (Gulf, Ed.) Houston, Tx, USA: Gulf Professional Publishing.

[2] Pettit, F. S., \& Goward, G. W. (1981). High temperature corrosion and use of coatings for protection. Metallurgical Treatises , 1, 603619.

[3] Solar Turbines A Caterpillar Company. (2007). Curso de operación y mantenimiento rutinario (Vol. 1). San Diego, C.A., USA: Solar Turbines Incorporated.
[4] Nageswara Rao , M. (2011). Materials for Gas Turbines - An Overview, Advances in Gas Turbine Technology. Intech Europe, University Campus STeP Ri. Rijeka: Intech.

[5] Shilke, P. W. (2004). Advanced Gas Turbine Materials and Coatings . (Ge, Ed.) Ge Power , 1 (356).

[6] Kurz. (2014). Gas turbine degradation. Turbomachinery Laboratory , 1 (1), 36.

[7] New Energy Connections. (2014). Mexico Oil\&Gas Review (Vol. 1). Mexico, Mexico, Mexico: LLC.

[8] Brulé, J. y Bount, A. (1989). Knowledge Acquisition. s.l. : Computing Mc. Graw Hill.

[9] Wilson, B. (1993). Sistemas: Conceptos, Metodologías y Aplicaciones (Vol. 1). México, México: Limusa editores.

[10] Alcaniz, R. (2011). Procesamiento Digital de Imagen, 37, Cataluña, España.

[11] Cuevas, E. (2017). Tratamiento de Imágenes con Matlab,

[12] Sossa, H. (2019) Procesamiento y análisis digital de imagen. Alfa Omega Ra-ma.

[13] Ramírez J., C. M. (2011). Redes neuronales para el procesamiento de imágenes, una revisión de última década (Vol. 9). RIEE.

[14] Sossa, H. (2019) Procesamiento y análisis digital de imagen. Alfa Omega Ra-ma. 